\section{Evaluation of antidepressant- like effect Lavandulifolia stachys in the forced swimming test in comparison with imipramine and fluoxetine}

\author{
Shirali Kharamin, ${ }^{1}$ Saeed Razmeh, ${ }^{1}$ \\ Mona Nabovvati, ${ }^{2}$ Karim Moradian, ${ }^{3}$ \\ Samaneh Rahimi, ${ }^{4}$ Maryam Orooji, ${ }^{5}$ \\ Laleh Taghavian, \\ Majid Kherad Mand Maher 6 \\ ${ }^{1}$ Yasuj University of Medical Sciences, \\ Yasuj; ${ }^{2}$ Iran University of Medical \\ Sciences, Tehran; ${ }^{3}$ Kermanshah \\ University of Medical Sciences, \\ Kermanshah; ${ }^{4}$ Shiraz University of \\ Medical Sciences, Shiraz; ${ }^{5}$ Alborz \\ University of Medical Sciences, Alborz; \\ ${ }^{6}$ University of Social Welfare and \\ Rehabilitation Sciences, Tehran, Iran
}

\begin{abstract}
Depression is a global problem associated with multiple social and health issues. In the present study, we analyzed the antidepressant effects of Lavandulifolia stachys, an herbal plant on forced swimming test (FST). In this study, 36 rats were used. We gavaged the aqueous extract of plant (50, $100,150 \mathrm{mg} / \mathrm{kg})$, imipramine and fluoxetine $(20 \mathrm{mg} / \mathrm{kg})$ as standard antidepressant drug and normal saline for control group for a week. Then, their behavioral responses including climbing, swimming and immobility were recorded during the 5-min FST. Our experiments showed significant effects of Lavandulifolia stachys on swimming and immobility but not effect on climbing behaviors. Imipramine and fluoxetine increased climbing and swimming, respectively, and both reduced immobility, compared to saline control. Finally, our results show the extract of Lavandulifolia stachys could play an important role in treatment of depression like fluoxetine.
\end{abstract}

\section{Introduction}

Depression is a serious mood disorder that interferes with an individual's thoughts, behavior, feelings and enjoying the life that afflicts several millions of the world population. ${ }^{1,2}$ It seems that signs and symptoms of depression are associated with decreased the neurotransmitters such as noradrenaline, 5-hydroxytryptamine (5-HT) and dopamine. ${ }^{3}$ The most efficient currently antidepressant including tricyclic antidepressants (TCAs) and selective serotonin reuptake inhibitors (SSRIs) have different side effects Which make difficult to use them. ${ }^{4,5}$ The avail of herbal medicine for the treatment of depression is on the rise because has lower side effects and sometimes have acceptable efficacy in comparison to the medications that used now. ${ }^{6,7}$ Lavandulifolia Stachys is an herbal medicine native to the eastern Mediterranean region and western Asia. ${ }^{8}$ This plant grows widely in many parts of Iran. ${ }^{9,10}$ It has been traditionally used for different medical purposes as, surgical dressing for wounds, sedative-hypnotic, strengthening the memory, relief of stress and treatment of diarrhea and chronic cough. ${ }^{11,12}$ Despite all these reports, no pharmacological study evaluates the antidepressant effect of this plant. Therefore, the present study evaluates the antidepressant effects of the aqueous extract of Lavandulifolia Stachys in the forced swimming test in rats.

\section{Materials and Methods}

Lavandulifolia Stachys were obtained from a local market in yasuj, Iran. It was authenticated by Department of Pharmacology, College of Science, Yasuj University. Dried leaves of the plant were converted to a fine powder. The powdered leaves $(260 \mathrm{~g})$ were macerated in a container with distilled water $(500 \mathrm{~mL})$ at room temperature for $48 \mathrm{hrs}$. Subsequently, was filtered and then was concentrated in a rotary evaporator under low pressure. The yield of extract was $31.6 \%(\mathrm{w} / \mathrm{w})$. Male Wistar rat $(\mathrm{n}=36), 240 \pm 20 \mathrm{~g}$ were obtained from the Animals House, Tehran University of Medical Sciences. The Rats were in cages of 5 at $22 \pm 1{ }^{\circ} \mathrm{C}$ and had free access to water and food. Imipramine hydrochloride and fluoxetine hydrochloride were used as reference drugs. After the gavage of aqueous extract $(50,100,150 \mathrm{mg} / \mathrm{kg})$, Imipramine and fluoxetine $(20 \mathrm{mg} / \mathrm{kg})$ and normal saline for a week, Rats were placed individually in a transparent cylinder (40 $\mathrm{cm}$ height $\times 20 \mathrm{~cm}$ in diameter). Two swim sessions were done. One for adaptation, rats were placed in water for 15 minutes followed 24 hrs later by a 5 -min test then the climbing, swimming and immobility behaviors of the rats were recorded. Increases in climbing and swimming and reduction in immobility were considered as behavioral responses consistent with an antidepressantlike action. The SPSS 22 was used for statistical analyses and $\mathrm{P}<0.05$ was considered as a significant level. The differences
Correspondence: Saeed Razmeh, Yasuj University of Medical Sciences, Yasuj, Iran. Tel.: +98.9171493122.

E-mail: srazmeh@yahoo.com

Key words: Lavandulifolia stachys, Fluoxetine, Imipramine, depression, forced swimming test.

Acknowledgments: the authors would thank Dr. Maryam Zaribafian for the editing.

Contributions: the authors contributed equally.

Conflict of interest: the authors declare no potential conflict of interest.

Funding: none.

Received for publication: 31 October 2018.

Accepted for publication: 6 November 2018 .

This work is licensed under a Creative Commons Attribution-NonCommercial 4.0 International License (CC BY-NC 4.0).

(C) Copyright S. Kharamin et al., 2019 Licensee PAGEPress srl, Italy

International Journal of Plant Biology 2019; 10:7458 doi:10.4081/pb.2019.7458

between the means of these parameters were compared using by using ANOVA test.

\section{Results}

The results show significant effects of swimming and immobility but not effect on climbing behaviors. Dunnett $\mathrm{t}$ test indicated that doses of $50,100,150 \mathrm{mg} / \mathrm{kg}$ of the extract significantly caused a reduction in immobility (5.16, 3.8, 5 respectively) and an increase in swimming $(24.3,23.5,26$ respectively), compared to control group $(\mathrm{P}<0.01)$ but did not show a dose-dependent effects of the extract on immobility, swimming and climbing behaviors. Imipramine and fluoxetine significantly increased climbing and swimming behaviors, respectively, and both reduced immobility, compared to control group $(\mathrm{P}<0.01$; Figures $1-3)$.

\section{Discussion and Conclusions}

The genus Stachys has about 300 species throughout the world. ${ }^{11}$ It uses traditionally in surgical dressing for wounds, sedative-hypnotic, strengthening the memory and relief of stress, anti-inflammatory and antimicrobial for the treatment of a chronic cough and diarrhea and anti-oxidative stress activity that documented in some 
studies. ${ }^{11,12}$ The FST is sensitive and rela-

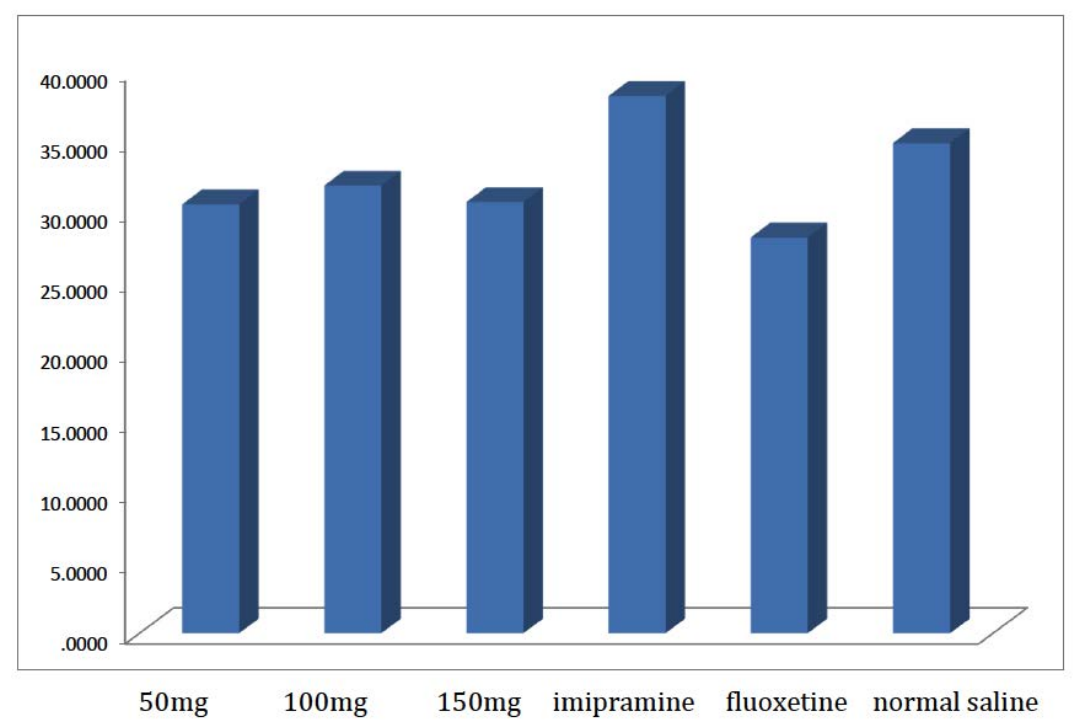

Figure 1. Effect of aqueous extract of plant $(50,100,150 \mathrm{mg} / \mathrm{kg})$ Lavandulifolia Stachys, imipramine, fluoxetine, normal saline on climbing. Data represents the mean activity counts per $5 \mathrm{~min}$. Comparisons were made using one-way ANOVA. $\mathrm{P}<0.01$.

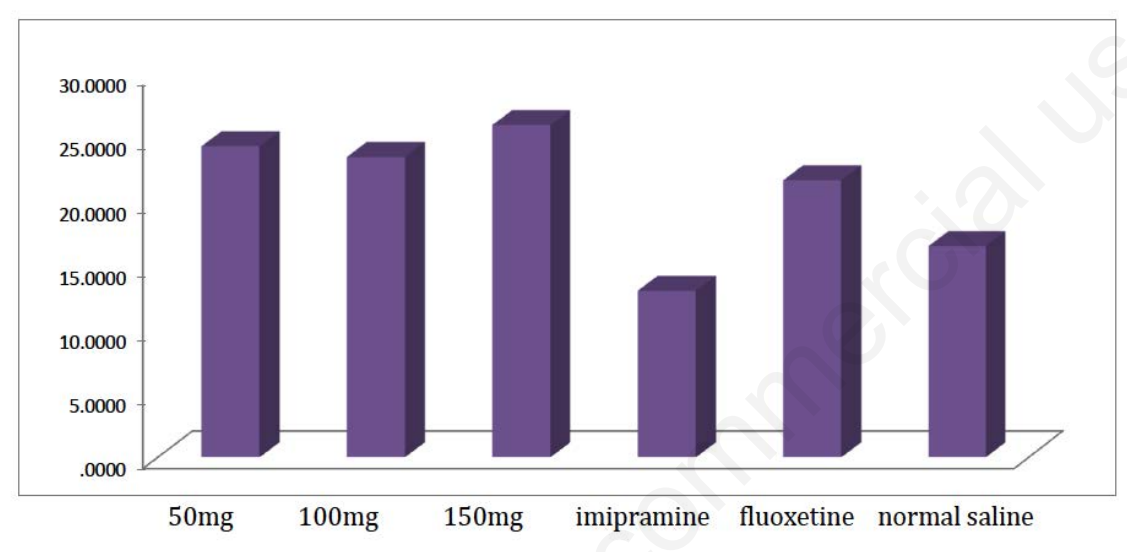

Figure 2. Effect of aqueous extract of plant $(50,100,150 \mathrm{mg} / \mathrm{kg})$ Lavandulifolia Stachys, imipramine, fluoxetine, normal saline on swimming. Data represents the mean activity counts per $5 \mathrm{~min}$. Comparisons were made using one-way ANOVA. $\mathrm{P}<0.01$.

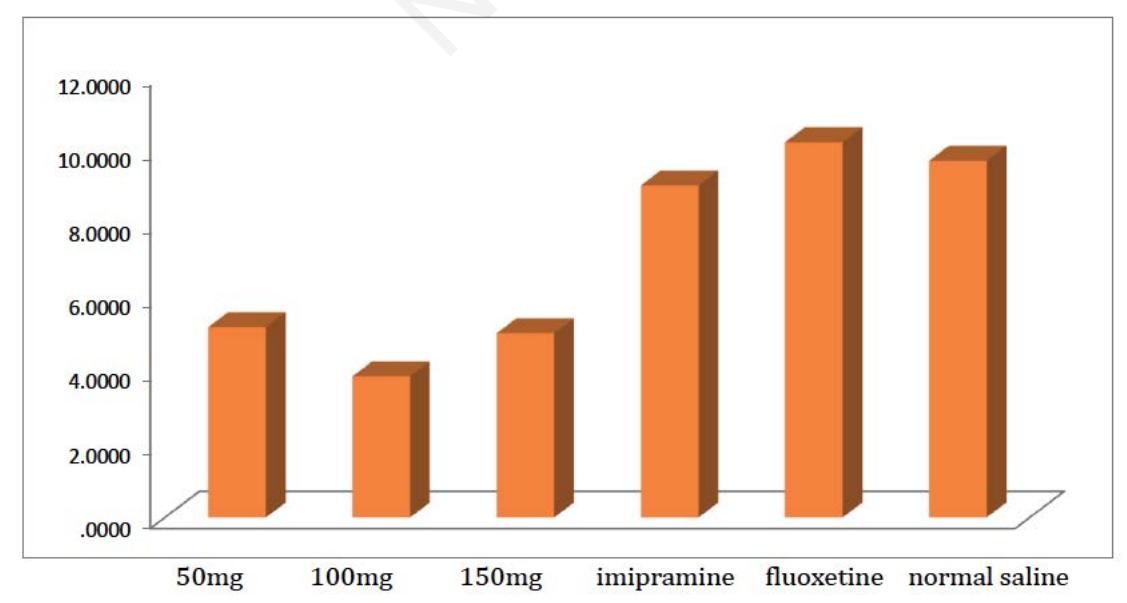

Figure 3. Effect of aqueous extract of plant $(50,100,150 \mathrm{mg} / \mathrm{kg})$ Lavandulifolia Stachys, imipramine, fluoxetine, normal saline on immobility Data represents the mean activity counts per 5 min. Comparisons were made using one-way ANOVA. $P<0.01$. tively specific for evaluation of all antidepressant drug including tricyclics, serotonin selective reuptake inhibitors, and $\mathrm{MAO}$ inhibitors. ${ }^{13}$ The serotonergic drugs such as fluoxetine have more effects on swimming, and tricyclic's has more effect on climbing. In a study by Gonzalo et al. that Antidepressant-like effects of Nicotine and fluoxetine in the rat forced swimming test shows that fluoxetine can reduce immobility and increase swimming. ${ }^{14}$ Another study by Helena et al. about the effect of imipramine in the rat forced-swimming test according to gender difference shows that the imipramine decreases the duration of immobility in male rats and frequency of immobility in female rats. ${ }^{15}$ In agreement with the previous report, the fluoxetine and imipramine increase the swimming and climbing respectively, and they decrease the immobility.to the best of our knowledge the antidepressant effect of Lavandulifolia Stachys on FST does not assay as yet. In one study by Rabbani and et al, that assessed the anxiolytic effects of four fractions of Stachys Lavandulifolia on the elevated plus-maze (EPM) model of anxiety showed Stachys Lavandulifolia has the anxiolytic effect with lower sedative activity than diazepam. ${ }^{16}$ The present study demonstrated that the aqueous extract of Lavandulifolia Stachys had significant antidepressant effects in rats. Different doses of the extract which were used in this study reduce immobility and enhance swimming, simultaneously. This study showed that the aqueous of the Lavandulifolia Stachys has antidepressant-like activity in the FST. In conclusion our study show that Lavandulifolia Stachys had a significant effect on rats and this effect is more on swimming like fluoxetine.

\section{References}

1. Katon W. The epidemiology of depression in medical care. Int J Psychiatry Med 2006;17:93-112.

2. Greenberg PE, Stiglin LE, Finkelstein SN, Berndt ER. The economic burden of depression in 1990. J Clan Psychiatry 2009;54:405-18.

3. Masi G, Brovedani P. The hippocampus, neurotrophic factors and depression. CNS Drugs 2011;25:913-31.

4. Blier P, De Montigny C. Current advances and trends in the treatment of depression. Trends Pharmacol Sci 1994;15:220-6.

5. Hazell P, O'Connell D, Heathcote D, Henry D. Tricyclic drugs for depression in children and adolescents. Cochrane Database Syst Rev 2002;2:CD002317. 
6. Gabriela GC, Javier AA, Elisa VA, et al. Antidepressant-like effect of Tagetes lucida Cav. extract in rats: involvement of the serotonergic system. Am J Chin Med 2012;40:753-68.

7. Blumenthal M, Goldberg A, Brinckmann J. Herbal MedicineExpanded Commission E Mongraphs. Newton, MA: Integrative Medicine Communications; 2000. p. 230-232.

8. Maleki N, Garjani A, Nazemiyeh H, et al. Potent anti-inflammatory activities of hydroalcoholic extract from aerial parts of Stachys inflata on rats. J Ethnopharmacol 2001;75:213-8.

9. Imam A, Shams-Ardekani MR, Mehregan I. The illustrated encyclopedia of herbal medicines. Translated to Persian and edited by a text by Chiej, Roberto entitled: The Macdonald Encylopedia of Medicinal
Plants. Research Center for Traditional Medicine and Pharmacognosy, Tehran: Shahid Beheshti University of Medical Sciences; 2003 p.192.

10. Shafie-Zadeh F. Lorestan medicinal plants. Lorestan University of Medical Sciences. Tehran: Hayyan press; 2002 p. 32.

11. Tundis R, Peruzzi L, Menichini F. Phytochemical and biological studies of Stachys species in relation to chemotaxonomy: a review. Phytochemistry 2014;102:7-39.

12. Sereshti M, Azari P, Rafieian M, Kheiri S. Use of herbal medicines by pregnant women in Shahrekord. J Reprod Infertil 2006; 7:125 -31.

13. Detke MJ, Rickels M, Lucki I. Active behaviors in the rat forced swimming test differentially produced by serotonergic and noradrenergic antidepressants.
Psychopharmacology 1995;121:66-72.

14. Vàzquez-Palacios $\mathrm{G}$, Bonilla-Jaime $\mathrm{H}$, Velàzquez-Moctezuma $\mathrm{J}$. Antidepressant-like effects of the acute and chronic administration of nicotine in the rat forced swimming test and its interaction with flouxetine. Pharmacol Biochem Behav 2004;78:165-1.

15. Tbarros HM, Ferigolo M. Ethopharmacology of imipramine in the forced-swimming test: gender differences. Neurosci Biobehav Rev 1998;23:279-86.

16. Rabbani M, Sajjadi SE, Jalali A. Hydroalcohol extract and fractions of Stachys lavandulifolia vahl: effects on spontaneous motor activity and elevated plus maze behaviour. Phytother Res 2005; 19:854-8. 